Abstract 997 Table 1 Kaplan-Meier survival curve for overall survival with groups

\begin{tabular}{|c|c|c|c|c|c|c|c|}
\hline & \multirow[t]{2}{*}{ Mean } & \multirow[t]{2}{*}{ Median } & \multirow{2}{*}{$\begin{array}{l}\% 1 \\
\text { year }\end{array}$} & \multirow{2}{*}{$\begin{array}{l}\% 3 \\
\text { year }\end{array}$} & \multirow{2}{*}{$\begin{array}{l}\% 5 \\
\text { year }\end{array}$} & \multicolumn{2}{|c|}{ Log rank } \\
\hline & & & & & & $\bar{x}^{2}$ & $p$ \\
\hline \multicolumn{8}{|c|}{ Groups } \\
\hline GP & 47.47 & - & 85.8 & 64.2 & 53.4 & 0.004 & 0.948 \\
\hline ED & 48.76 & - & 81.1 & 67.3 & 57.8 & & \\
\hline
\end{tabular}

overall survival rates between the two groups did not show statistical difference $(p=0.948)$.

When comparing the overall survival rates in each stage of ovarian cancer, there was no statistical significant difference between the 1- year, 3-year and 5-year overall survival in ovarian cancer patients referred from GP and ED with ovarian cancer in stage $1 \quad(p=0.262)$, stage $2(p=0.350)$, stage 3 $(p=0.906)$ and stage $4(p=0.224)$.

Conclusion* The mode of referral of ovarian cancer patients does not affect the overall survival for any FIGO stage $(p=0.948)$. Women with ovarian cancer, at presentation, irrespective of the mode of referral should be assessed by the gynaecological oncology team to offer timely treatment with initial surgery or neo-adjuvant chemotherapy.

\section{EXPLORING THE REASONS BEHIND OPTING FOR PALLIATIVE CHEMOTHERAPY OR NO TREATMENT IN ADVANCED OVARIAN CANCER PATIENTS}

A Barakat*, A Ismail, Q Davies, S Chattopadhyay. University Hospitals of Leicester, GynaeOncology , UK

10.1136/ijgc-2021-ESG0.502

Introduction/Background* The role of palliative chemotherapy in treating advanced ovarian cancer remains unclear. Some evidence suggests that chemotherapy has a role in relieving symptoms in advanced ovarian cancer. This study aims to explore the reasons why patients were managed by palliative chemotherapy or no treatment. Moreover, to evaluate the effectiveness of palliative chemotherapy in advanced ovarian cancer.

Methodology A retrospective study was conducted in the University Hospitals of Leicester from January 2015 to January 2020 involving 54 patients with advanced ovarian cancer: 34 patients received palliative chemotherapy and 20 patients had no treatment. Data was statistically analysed, and the overall survivals were calculated from Kaplan Meier Curves.

Result(s)* In patients undergoing palliative chemotherapy, 27 $(79.4 \%)$ were not suitable for debulking surgery, $4(11.8 \%)$ died before surgery, $3(8.8 \%)$ patients declined surgery. Twenty patients had no treatment: $13(65 \%)$ died before chemotherapy and $5(25 \%)$ were not fit for any treatment, 1 (5\%) patient died before surgery and $1(5 \%)$ patient declined surgery.

The 12- and 18-months overall survival in patient who had chemotherapy were $55.9 \%$ and $38.2 \%$ respectively, while it was $5 \%$ and $0 \%$ in those not having any treatment. The overall survival rates were significantly higher in the patients receiving palliative chemotherapy $(\mathrm{p}<0.001)$.

Conclusion* Palliative chemotherapy increases the overall survival in advanced ovarian cancer patients, but the cost of

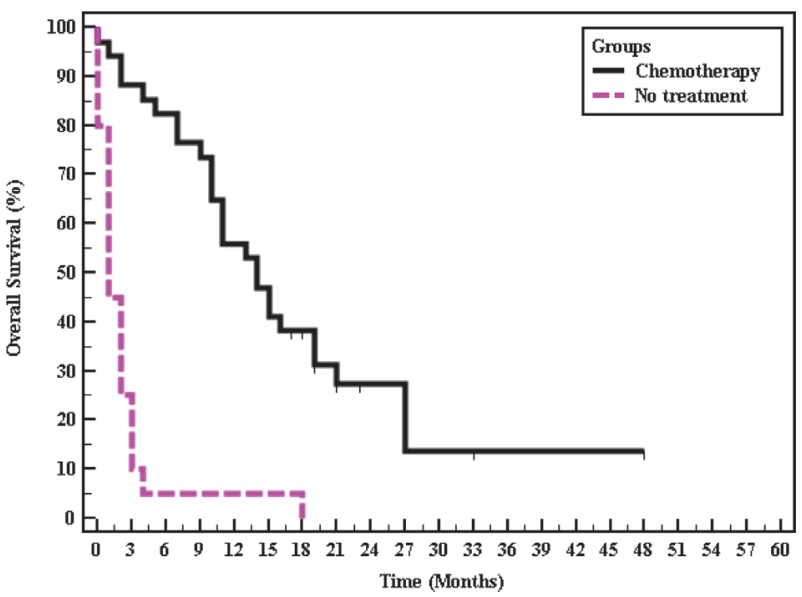

Abstract 998 Figure 1 Kaplan-Meier survival curve for overall survival with groups

Abstract 998 Table 1 Kaplan-Meier survival curve for overall survival with groups

\begin{tabular}{|c|c|c|c|c|c|c|}
\hline & \multirow[t]{2}{*}{ Mean } & \multirow[t]{2}{*}{ Median } & \multirow{2}{*}{$\begin{array}{l}\% 12 \\
\text { month }\end{array}$} & \multirow{2}{*}{$\begin{array}{l}\% 18 \\
\text { month }\end{array}$} & \multicolumn{2}{|l|}{ Log rank } \\
\hline & & & & & $\overline{x^{2}}$ & $p$ \\
\hline \multicolumn{7}{|l|}{ Groups } \\
\hline Chemotherapy & 17.91 & 14.0 & 55.9 & 38.2 & $35.466^{*}$ & $<0.001^{\star}$ \\
\hline No treatment & 2.30 & 1.0 & 5.0 & 0.0 & & \\
\hline
\end{tabular}

treatment and the effect on quality of life should be balanced to meet the patients' expectations.

\section{ROBOT ASSISTED LAPAROSCOPIC STAGING SURGERY FOR EARLY STAGE BORDERLINE OVARIAN TUMOUR}

SD RS*, T James, R Ranade. Narayana Health City, Gynaecological Oncology, Bangalore, India

\subsection{6/ijgc-2021-ESGO.503}

Introduction/Background* Till recently primary surgery for ovarian cancer and borderline ovarian tumours was done by laparotomy irrespective of the stage of the disease. Slowly the role of minimally invasive surgery in selected cases of borderline ovarian tumours and early stage ovarian cancers is becoming well known. ${ }^{1}$

Methodology A 42 year old P2L2, previous 1 LSCS with history of Heavy Menstrual Bleeding and Abdominal pain not responding to medical management was evaluated outside. A pelvic ultrasound showed multiple intramural uterine fibroids, largest measuring $3 \mathrm{~cm}$ and a $6 \times 4 \times 4 \mathrm{~cm}$ mass in left adnexa away from the left ovary, with both ovaries appearing normal and visualised separately. Her Ca 125 was 121 IU/L. Magnetic Resonance Imaging of the pelvis was reported as multiple intramural fibroids and propable broad ligament mass. She was referred to our hospital for management. Patient underwent Robot assisted laparoscopic Staging with hysterectomy, B/ L Salpingo-oopherectomy, Frozen section of the left adnexal mass, Bilateral Pelvic lymph node dissection, Omental biopsy, pelvic peritoneal biopsy. 